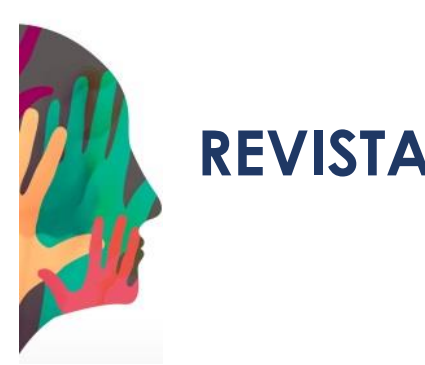

EXTENSÃO \& CIDADANIA

v. 8, n. 13, p. 301-316, jan./jun. 2020.

ISSN 2319-0566

DOI: $10.22481 /$ recuesb.v8i13.7110

\title{
ATIVIDADES DE EXTENSÃO E AS CONCEPÇÕES DE CIENTISTAS DE ALUNOS DO SEXTO ANO DO ENSINO FUNDAMENTAL
}

\author{
EXTENSION ACTIVITIES AND THE CONCEPTIONS OF SCIENTISTS OF \\ STUDENTS OF THE SIXTH YEAR OF FUNDAMENTAL EDUCATION
}

\author{
Juliana Ricarda de Melo ${ }^{1}$ \\ Jeane Cristina Gomes Rotta ${ }^{2}$
}

\begin{abstract}
Resumo: A concepção de cientistas apresentada pelos estudantes pode ser reflexo de seu cotidiano e, também, influenciada pela mídia. Muitas vezes, estas concepções veiculadas são estereotipadas e acabam não refletindo a visão real do trabalho de um cientista. Neste sentido, o objetivo deste trabalho foi, a partir de atividades de um projeto de extensão, investigar as concepções de cientistas de alunos de quatro escolas públicas e propor ações didáticas que possibilitassem a ressignificação dessas concepções. A metodologia desta pesquisa foi qualitativa e os dados obtidos pelos questionários e desenhos realizados pelos estudantes foram categorizados. Os resultados indicaram que a maioria dos estudantes apresenta uma visão de cientistas influenciada por programas transmitidos na televisão. A partir das atividades desenvolvidas no projeto de extensão, foi perceptível o entusiasmo dos estudantes pelas ações e muitos conseguiram perceber com mais clareza a figura do cientista e a pluralidade de seu trabalho científico.
\end{abstract}

Palavras-chave: Concepções de cientista. Extensão universitária. Ensino de ciências.

\begin{abstract}
The students' conception about scientists can be a reflection of their daily life and also influenced by the media. Often, these conceptions conveyed are stereotyped and end up not reflecting the real view of a scientist's work. In this sense, the objective of this work was, from the activities of an extension project, investigate the students' conceptions about scientists of four public schools and propose didactic actions that would allow the resignification of these conceptions. The methodology of this research was qualitative and the data obtained by the questionnaires and drawings made by the students were categorized. The results indicated that the majority of students present a view of scientists influenced by

\footnotetext{
${ }^{1}$ Mestre em Ensino de Ciências, pela Universidade de Brasília; professora da Secretária da Educação do Distito Federal. E-mail: jurm.ciencias@gmail.com

${ }^{2}$ Doutora em Ciências pela Universidade de São Paulo (USP); professora Associada da Universidade de Brasília. E-mail: jeanerotta@gmail.com
} 
programs broadcast on television. From the activities developed in the extension project, the students' enthusiasm for actions was noticeable and many managed to perceive more clearly the figure of the scientist and the plurality of his scientific work.

Keywords: Concept of scientist. University extension. Science teaching.

\section{Introdução}

A importância de uma visão adequada do papel das Ciências e dos cientistas é amplamente discutida, devido a sua importância para a for mação cidadã dos estudantes (PRAIA; GIL-PÉREZ; VILCHES，2007; SCHEID; FERRARI; DELIZOICOV， 2016; CAVALLI; MEGLHIORATTI, 2018). O entendimento pela sociedade das atividades dos cientistas e sobre como são realizadas as pesquisas podem propiciar discussões sobre a ética e a utilidade destas pesquisas. Assim, compreender o que é ciência tornou-se fundamental para a atuação crítica dos indivíduos em questões relacionadas aos impactos da relação ciência e sociedade (PÉREZ et al., 2001; REIS; RODRIGUES; SANTOS, 2006). No entanto, alguns fatores contribuem para uma visão inadequada sobre esse tema, como as imagens da ciência veiculadas pelos meios de comunicação social e a inexistência de reflexões críticas em relação a estas imagens nas escolas (REIS; GALVÃO, 2006, CARVALHO; COSTA; ROCHA, 2019; VAZ; BATISTA; ROTTA, 2021).

A escola pode intermediar essa aproximação da população com as Ciências, pois nesta instituição ocorre um grande fluxo de troca de informações, como também, em muitos casos, é o local onde ocorre o primeiro contato entre o conhecimento científico e a criança (SAVIANI, 2011). Neste contexto, acreditamos que ensino de Ciências pode favorecer aos estudantes conhecerem e terem familiaridade com assuntos relativos às Ciências. Assim, projetos que auxiliem a desmitificar esta visão estereotipada das Ciências e dos cientistas contribuem para uma visão crítica da ciência e da tecnologia (RANGEL, 2005; SANTANA, 2014).

A extensão universitária concebida como um elo capaz de associar a pesquisa e o ensino tem possibilitado a troca de saberes entre a comunidade, a universidade e a produção de conhecimento. Nesse sentido, o projeto de extensão "O ensino de Ciências e o desafio da 
aproximação Universidade-Escola”, desenvolvido há 14 anos pela Universidade de Brasília, campus de Planaltina, tem realizado atividades pedagógicas com licenciandos de Ciências Naturais nas escolas públicas desta região, visando aproximar as Ciências do cotidiano dos estudantes.

As atividades são desenvolvidas em uma metodologia que favorece a formação inicial dos licenciandos, a partir do conhecimento da realidade das escolas, seu futuro ambiente de trabalho. Favorecendo, assim, a troca de conhecimentos com os professores de Ciências, atuantes nas escolas, e possibilitando contribuições para a formação inicial e continuada de professores de Ciências (ROTTA et al., 2012; SANTOS; FARIAS; ROTTA, 2019).

O objetivo desse trabalho é relatar a pesquisa realizada em escolas públicas de ensino fundamental sobre a concepção dos alunos sobre cientistas, bem como, as ações resultantes dessa pesquisa para auxiliarem na ressignificação dessas concepções, a partir de um projeto de extensão universitária.

\section{Ensino de Ciências}

O ensino de ciências pode influenciar as concepções de Ciências de alunos e professores, portanto, é necessário compreendermos um pouco sobre este ensino no Brasil. Entre os anos de 1960 a 1980, houve um enfoque do modelo tecnicista de educação, que persiste até os dias atuais, que é centrado "nas ideias de racionalidade, eficiência e produtividade, que são as características básicas da chamada pedagogia tecnicista" (SAVIANI, 2011, p. 77). Entretanto, essa pedagogia limita o aluno à repetição e à fragmentação das ideias, o que não é adequado para as necessidades atuais pontuadas por nossa sociedade. Ou seja, a formação de cidadãos reflexivos e autônomos, capazes de escolherem os meios de informação que lhe são necessários e atuarem conscientemente em diferentes situações da realidade (KRASILCHIK, 1992; OLIVEIRA; ARAÚJO, 2005).

A partir dos anos de 1980, com a incorporação de ideias construtivistas, socioculturais e o movimento das relações entre Ciência-Tecnologia e Sociedade (CTS) na educação, o ensino de ciências no Brasil passou a considerar a relevância de propostas pedagógicas contextualizadas, que propiciasse a aprendizagem efetiva dos alunos e o desenvolvimento de 
uma visão integrada do funcionamento da sociedade (KRASILCHIK, 1992; ANGOTTI; AUTH, 2001; TEIXEIRA, 2003).

Esta mudança de concepção ocorreu, também, em virtude das contribuições da psicologia do desenvolvimento com bases em pesquisas de Vigotsky e Wallon. Neste contexto, percebe-se a complexidade das relações de ensino e aprendizagem, que passam a ser reconhecidos como processos que envolvem não só a memorização, mas a preparação física, psicológica e cognitiva do sujeito. De forma mais detalhada, a teoria de Vigotsky propõe etapas para que ocorra a aprendizagem, que são influenciadas pelas interações sociais (QUEIRÓZ; MACIEL; BRANCO, 2006).

De acordo com essa perspectiva, a aprendizagem da criança é influenciada por seu meio e pelas interações entre o que ela já sabe e o que pode aprender. Nesse processo, a linguagem tem um importante papel, pois é o meio de veiculação das informações (SOUZA FILHO, 2008). Portanto, os diálogos nas aulas de Ciências possibilitam a contextualização e relação com a História e Filosofia das Ciências, promovendo um ensino e aprendizagem das Ciências mais condizentes com as atuais perspectivas pedagógicas. Entretanto, isso só ocorre quando o professor está comprometido com a formação de um sujeito integral, atuando em suas vertentes gnosiológica, psicológica e psicossocial (TASSARA; ARDANS, 2005).

No ensino de ciências, essa mediação pode ocorrer com a inserção da reflexão sobre a História das Ciências, levando a questionamentos sobre as pesquisas científicas, as motivações e as controvérsias éticas, possibilitando o desenvolvimento do espírito investigativo dos estudantes e esclarecendo o que é o trabalho científico (ANGOTTI; AUTH, 2001; REIS, RODRIGUES; SANTOS, 2006; SCHEID; FERRARI; DELIZOICOV, 2016). A história das Ciências pode aproximar o estudante da trajetória da humanidade, possibilitando a discussão e a compreensão da ciência como resultado de uma criação humana, sujeita a erros e acertos, contribuindo, portanto, para que o sujeito possa conhecer a evolução da ciência e a forma como ela se organiza. Isto permite posicionamentos críticos e reflexivos frente às questões cotidianas, o que reflete diretamente na organização da sociedade (DRIVER et al., 1999; TEIXEIRA, 2003).

Para Reis, Rodrigues e Santos (2006), o professor pode proporcionar momentos para que o estudante ressignifique uma visão inadequada de ciência e de cientista que é transmitida 
pelos diversos meios de comunicação, possibilitando a compreensão de como ocorre realmente a produção científica. Isso desmitifica a ideia da ciência produzida em laboratórios e por cientistas de jaleco com vidrarias e elementos coloridos, além do fato de que a ciência não serve só para descobrir coisas novas, mas também para revisar conhecimentos já adquiridos (TEIXEIRA, 2003).

\section{Imagem de Cientistas}

A imagem que os estudantes têm de cientistas reflete o imaginário social, uma vez que estes recebem influências semelhantes às dos outros membros que compõem a sociedade, como seus pais, amigos e vizinhos (KOMINSKY; GIORDAN, 2002; CAVALLI; MEGLHIORATTI, 2018). Essa concepção do cientista é estruturada ao longo da vida do sujeito, que se depara com diversas imagens de cientistas e concepções de ciência, que variam de acordo com o meio de veiculação, sejam as aulas de ciências ou um filme de suspense (RANGEL, 2005; PECHULA, 2007).

A visão de cientista que o estudante manifesta através de desenhos, histórias ou conversas, que envolve o trabalho científico, pode ser um indício das relações que ele mantém com a ciência, uma vez que revela seus pré-conceitos em relação ao tema e, assim, a maneira como entende a ciência e para o que ela serve (KOMINSKY; GIORDAN, 2002; REIS, RODRIGUES; SANTOS, 2006; REIS; GALVÃO, 2006). Especificamente no ensino de ciências, a caracterização de quem produz o conhecimento pode expressar as contribuições das aulas de ciências, refletindo os pressupostos em ciências que o professor traz desde a sua formação universitária (PÉREZ et al., 2001).

Reis, Rodrigues e Santos (2006) afirmam que aulas, cuja História e Filosofia das Ciências são consideradas como parte do currículo de Ciências, podem estimular os estudantes a buscar mais informações em Ciências, bem como aproximá-los do trabalho científico, resultando em uma visão menos distorcida desse trabalho. Contudo, nem sempre essa é a realidade do ensino, desde o nível básico até o universitário, são repassadas visões deturpadas da realidade científica, moldando uma visão mental de cientista que recai no 
molde positivista da ciência, além de muitas vezes privilegiar apenas a figura masculina de cientistas (CARVALHO; COSTA; ROCHA, 2019; VAZ; BATISTA; ROTTA, 2021).

Apesar de já ultrapassado há alguns anos o modelo cartesiano de ciência, rígido e verdadeiro, este ainda persiste no discurso de muitos professores e nas caricaturas de cientistas em desenhos animados, filmes, revistas. A mídia veicula a imagem científica que a maior parte da sociedade tem acesso. Nela, as informações são repassadas de maneira compacta e simples, com maior apelo visual do que conteudista, tentando sanar qualquer dúvida, ou seja, procura tornar o conhecimento fácil e eficaz. Desse modo, Pechula assinala que:

(...) os veículos de comunicação de massa, quando se propõem a informar as descobertas e invenções científicas, o fazem em nome do conhecimento científico. Entretanto, ao produzirem a informação acerca da descoberta, ou criação científica, empregam alguns signos que representam o mundo ingênuo, que apresenta a ciência enquanto um conhecimento pronto e solucionador de todos os problemas. Nessa perspectiva, a presença dos signos que promovem um imaginário social ingênuo, coloca este imaginário em confronto com a perspectiva científica elaborada pelas universidades e instituições especializadas. (PECHULA, 2007, p. 216)

O cinema também contribui para a imagem do cientista, com os filmes sobre a vida de gênios ou criações problemáticas surgidas de experiências mal sucedidas de cientistas, e até mesmo armas para planos mirabolantes (RANGEL, 2005, CAVALLI; MEGLHIORATTI, 2018). A influência do cinema, desenhos e outros meios de entretenimento e informações, na imagem de cientista dos estudantes, é confirmada pelos resultados de diferentes pesquisas sobre a imagem de cientista entre estudantes, conforme apresentada no estudo de Reis, Rodrigues e Santos que constatam:

(...) as ideias utilizadas pelos alunos, tanto nos desenhos, como nos enredos das histórias, foram retiradas, frequentemente, de desenhos animados, séries televisivas e filmes (por exemplo, Sonic, Tio Patinhas, Inspector Gadget e Harry Potter). (...) Dessa forma, os meios de comunicação social parecem assumir um papel de destaque na veiculação de diversas imagens estereotipadas sobre as características pessoais ou a atividade do profissional do cientista. (REIS; RODRIGUES; SANTOS, 2006, p. 68)

Quanto à visão de cientista descrita nas pesquisas, estas caracterizam duas imagens do cientista presentes entre as crianças e adolescentes. A primeira é caracterizada por uma figura do sexo masculino de cabelos brancos e que trabalha em um laboratório. O cientista é sério, 
não possui vida social ou é distante da família, é poderoso e pode trazer benefícios ou não para a sociedade, dependendo do estudo que faz (CAVALLI; MEGLHIORATTI, 2018). Enquanto a segunda imagem representa um cientista "maluco", do sexo masculino, com ar brincalhão, que provoca explosões, cria máquinas malucas e monstros (REIS, RODRIGUES; SANTOS, 2006; REIS; GALVÃO, 2006).

São poucos os estudantes que apresentaram uma visão crítica do trabalho científico e, para muitos, o cientista é visto como uma figura necessária para a sociedade, pois realiza estudos e busca melhorar a qualidade de vida das pessoas com invenções novas (REIS; GALVÃO, 2006). Além disso, a imagem estereotipada do cientista vai se sedimentando ao longo da vida do estudante. Estudos realizados mostram que, no Ensino Médio, esta visão equivocada sobre o cientista é bem mais presente do que no Ensino Básico (REIS; GALVÃO, 2006; KOMINSKY; GIORDAN, 2002).

\section{Metodologia}

Esta foi uma pesquisa qualitativa que considera a realidade social, na qual os fenômenos se expressam, bem como a sua mutabilidade (LÜDKE; ANDRE, 1986). Nesta pesquisa, constituída por dois momentos, participaram seis turmas de sexto ano do ensino fundamental, de quatro escolas públicas da região de Planaltina-DF.

No primeiro momento, foi entregue um Termo de Consentimento Livre e Esclarecido e, posteriormente, foi solicitado aos alunos que respondessem a um questionário diagnóstico contendo cinco questões. Uma destas questões solicitava aos estudantes que desenhassem um cientista no seu ambiente de trabalho e uma questionava o que é ciência. Os outros questionamentos buscaram conhecer a concepções destes estudantes sobre o que o cientista faz e onde já foi visto.

Foram obtidos 152 questionários e a análise foi realizada a partir da criação de categorias produzidas das palavras-chave contidas nos questionários na maioria dos casos (LÜDKE; ANDRE, 1986). Nos desenhos realizados pelos estudantes, foram analisados os seguintes aspectos: elementos do cenário; área da ciência retratada e como o cientista se encontrava: solitário ou trabalhando com outras pessoas. 
Posteriormente, entrevistaram-se dois estudantes de cada turma (totalizando 12 entrevistas) para complementar os dados fornecidos nos questionários. Portanto, diferentes instrumentos de obtenção de dados foram utilizados, auxiliando na prevenção de análises distorcidas da realidade pelo uso de um único instrumento e facilitando o aprofundamento das questões a serem tratadas (REIS; RODRIGUES; SANTOS, 2006).

No segundo momento, foram discutidas as questões dos questionários e apresentação de slides que abordaram a vida de cientistas e visitas à universidade, nas quais puderem conhecer a rotina de alguns cientistas de diferentes áreas do conhecimento. Essas visitas acontecem regularmente e são desenvolvidas atualmente pelos licenciandos em Ciências Naturais, participantes do projeto de extensão "O ensino de Ciências e o desafio da aproximação Universidade-Escola”.

\section{Resultados e Discussão}

A análise do questionário, realizada no primeiro momento das atividades de extensão, apresentou uma grande variedade de respostas. Entre elas, categorizamos que 30\% alunos que participaram das pesquisas consideram que os cientistas estudam Ciências; $22 \%$ disseram que estudam Biologia; 21\% Física e as demais respostas indicaram várias outras áreas das Ciências, como Matemática, Química, Ciências da Saúde, entre outros.

As entrevistas realizadas apresentaram a mesma pluralidade sobre a questão. Estes resultados podem ter sido influenciados pelos conteúdos de ciências que estes estudantes aprendem nas aulas do sexto ano, pois para muitos deles, os cientistas estudam Ciências, que é tudo que eles aprendem nas aulas desta disciplina. Este indicativo está presente em suas respostas que citam itens específicos estudados pelos cientistas como: solo, água, estrelas, planetas e plantas, assuntos abordados nas escolas pelos professores nas aulas de Ciências.

Neste contexto, observamos a importância das aulas de Ciências e do professor desta disciplina, conforme discutido por Santana (2014). As questões relativas à História das Ciências são discutidas durante as aulas, possibilitam a ampliação do conhecimento do aluno sobre o que é Ciência e como é elaborada, sendo resultado de uma criação humana, sujeita a 
controvérsias (REIS, RODRIGUES; SANTOS, 2006; SCHEID; FERRARI; DELIZOICOV, 2016).

Quando questionados em relação a que um cientista faz durante a sua vida, a resposta mais citada por $39 \%$ foi “estuda". Entre estes estudantes, $21 \%$ responderam que os cientistas fazem descobertas; $14 \%$ que trabalham; $12 \%$ relataram que fazem pesquisas e $11 \%$ responderam que fazem experiências. Apenas 3\% responderam que o cientista realiza atividades cotidianas inerentes ao ser humano, como comer, dormir ou relacionar-se com outras pessoas.

Observamos que estes dados corroboram com a maioria das pesquisas que abordam este tema e que consideram os cientistas como seres diferenciados da maioria dos seres humanos (PECHULA, 2007; CARVALHO; COSTA; ROCHA, 2019). Estas imagens podem afastar os estudantes das carreiras científicas, por considerá-las distantes das pessoas comuns. Durante as entrevistas, algumas respostas apontaram para uma imagem salvadora do cientista, que pesquisa e estuda buscando o bem para a humanidade, como mostrado na fala seguinte:

Ele estuda as melhores coisas e as piores, para que os seres vivos tenham uma vida melhor. (E11)

Outro aluno, (E 67), relatou que o cientista durante a vida estudava para depois comunicar as informações para as pessoas através de reportagens e entrevistas na televisão. Observamos que, nestes resultados, estão presentes a imagem veiculada pelos meios de comunicação, de cientista em laboratório trabalhando em meio a pilhas de livros, excluindo o contexto cotidiano do pesquisador como um ser humano normal, com necessidades e atividades rotineiras como comer, dormir, relacionar-se com outras pessoas, entre outros (KOMINSKY; GIORDAN, 2002).

Em relação ao questionamento "onde você já viu um cientista", a resposta mais comum foi na televisão por $41 \%$ dos participantes, seguida por "nunca vi", com $21 \%$ das respostas, poucas foram as referências a computadores ou livros, com 1,05\% das respostas. As demais respostas foram variadas e indicaram que os estudantes viram cientistas em laboratórios, hospitais e na escola. 
Entre os 12 alunos que foram entrevistados, dois afirmaram terem visto um cientista na escola fazendo experiências. Um deles (E 53) especificou que o cientista estava mexendo com plantas; outro (E 106) relatou ter encontrado um cientista no campus de uma universidade próxima à escola onde estuda, quando foi fazer uma pesquisa escolar com o irmão.

A partir destas respostas, observa-se novamente que a mídia é a principal responsável pela divulgação da imagem de um cientista. Entretanto, é preciso que fiquemos atentos, pois inúmeras vezes a imagem veiculada é estereotipada e desvinculada da realidade. Portanto, há necessidade de que o professor, durante as aulas de Ciências, proporcione espaços para realização de diálogos que possam conduzir a reflexão sobre esta imagem inadequada dos cientistas (CAVALLI; MEGLHIORATTI, 2018).

A última pergunta questionava a visão dos estudantes sobre a Ciência. Entre as respostas, 33\% indicaram como um estudo ligado à área de Biologia (estudo das plantas, seres vivos, animais, etc.); $20 \%$ um estudo relacionado à Física e 15\% apresentaram respostas variadas como buscar solução para os problemas, estudar sobre as coisas, fazer coisas boas para a humanidade, revelar a verdade, o estudo de coisas extraordinárias, entre outros, enquanto, $32 \%$ dos estudantes não souberem responder. No geral, percebemos que os estudantes compreendem a Ciência como o estudo de alguma coisa e muitas destas respostas estão de acordo com as considerações de alunos de ensino superior de um curso de Biologia sobre o tema (SCHEID; FERRARI; DELIZOICOV, 2007).

Contraditoriamente ao expressado nos desenhos, nem um estudante fez referência à Química como uma área de estudo das Ciências, possivelmente, pelo cronograma escolar do sexto ano não contemplar, de forma explícita, os temas e conteúdo relativos à Química. Neste caso, acreditamos que a imagem do cientista desenhada por ter reflexo de uma imagem de cientista muito veiculada na mídia.

Identificamos em 45\% dos desenhos elementos relacionados à Química, como a existência de bancadas e vidrarias com líquidos coloridos e em 30\% faziam referência à Física, com cientistas observando o céu ou em trajes espaciais fora da Terra. No caso da Biologia, 23\% dos desenhos apresentavam o estudo das plantas. Poucos desenhos, 2\%, referiam-se ao cientista como um professor, com quadro e alunos, em alguns casos. Em 
pesquisa realizada por Cavalli e Meglhioratti (2018), também, houve a identificação na maioria dos desenhos de elementos que relacionavam os cientistas às áreas da Física, Química e Biologia.

Os desenhos analisados, em sua maioria, foram discordantes com as respostas dos estudantes participantes ao questionário. Na questão 1, as respostas foram predominantemente relacionadas à Biologia e à Física, os desenhos representaram a Química e a Física, isso pode ser reflexo dos conteúdos estudados na escola, no sexto ano, que enfocam mais os conteúdos de Biologia e Física. Enquanto, a imagem repassada pelos meios de comunicação enfatiza a visão de um químico, dentro de um laboratório com vidrarias e fazendo reações explosivas. Portanto, a educação científica tem por base a discussão e clarificação das ideias nos estudantes acerca dos princípios e das dicotomias entre a ciência real e a com fins de entretenimento (SANTANA, 2014).

No entanto, não foi identificada nos desenhos a representação do cientista excêntrico fazendo coisas malucas, como relatado na literatura (REIS; SILVA, 2006). Apenas em uma escola, houve grande incidência do cientista com a língua para fora e, em alguns casos, com o cabelo arrepiado, justificado com o fato de o cientista tomar choque:

Nunca vi um cientista, mas tenho vontade de ver, acho que eles são meio loucos, eles tomam choque pro cabelo ficar arrepiado. (E09)

Observamos que os estudantes representaram na maioria um cientista jovem vestindo jaleco, não houve grande incidência de óculos ou pessoas carecas, remetendo a imagem de cientista como velho, sério, de acordo com o estereótipo apresentado na literatura (KOMINSKY; GIORDAN, 2002). O ambiente de trabalho do cientista foi representado por um laboratório nos desenhos por $60 \%$ dos estudantes e $26 \%$ apresentaram os cientistas trabalhando em outros ambientes, como fora da Terra, ambientes abertos em estudo com plantas ou observando as estrelas. Em 14\% dos desenhos, não foi possível identificar em que contexto o cientista estava inserido por falta de elementos.

A figura feminina foi representada por $39 \%$ dos estudantes, mas ainda assim, inferior à masculina. Quanto à socialização do cientista, apenas em 11,84\% não estavam sozinhos, os demais apresentavam com um colega (do mesmo sexo ou não) ou com um grupo de pessoas 
que podem ser identificadas como estudantes. De acordo com Cavalli e Meglhioratti (2018), a presença de mulheres em desenhos realizados por estudantes ainda é pequena, quando comparada a presença masculina. Isto é resultado de um contexto histórico que limitou a participação das mulheres nas ciências e evidenciou apenas as descobertas científicas masculinas (VAZ; BATISTA; ROTTA, 2021).

No segundo momento desta proposta, foram realizadas as ações após a análise dos questionários. Estas constaram de apresentação de slides sobre a vida dos cientistas e o papel das Ciências e tiveram por objetivo explicitar que o cientista não é apenas aquele que trabalha em laboratório ou vive só. Muitos têm família e suas descobertas são decorrentes de grupos de pesquisas e embasadas em pesquisas de outros cientistas. Figuras de diferentes cientistas (mulheres e homens) foram representadas e comentadas, assim como imagens de diferentes locais onde um cientista pode trabalhar (universidade, laboratórios, ao ar livre e sala de aula, por exemplo).

Neste contexto, a História das Ciências pode auxiliar a elucidar os contextos que mostram como foi a vida dos cientistas de ambos os sexos, as superações para o reconhecimento de suas descobertas e o momento histórico em que eles viviam, permitindo reconhecer estas pessoas, como qualquer ser humano, têm dúvidas e enfrentam desafios (REIS; RODRIGUES; SANTOS, 2006).

Durante os diálogos, os estudantes se mostraram bastante participativos e se surpreenderam ao perceber que para ser cientista não é necessário ser sempre o melhor da classe ou o mais esquisito. Quando viram a imagem do Stephen Hawking, os estudantes, de forma geral, ficaram bastante impressionados por existir um cientista com deficiências. Assim como se mostraram surpresos ao descobrir que Einstein nem sempre foi considerado um gênio e que Marie Curie era casada e tinha duas filhas.

Após estas discussões em sala de aula, os estudantes visitaram o campus de Planaltina da Universidade de Brasília, tiveram a oportunidade de conhecer diferentes professores pesquisadores, ou seja, cientistas em seu local de trabalho. Os estudantes demonstraram muito entusiasmo e fizeram perguntas aos professores sobre conhecimentos de âmbito científico como também pessoais: como resolveram ser cientistas? Você tem família? É legal ser cientista? Como é seu trabalho? 
De volta à escola, todos avaliaram como uma experiência positiva e, segundo a professora da turma, comentaram sobre o acontecimento ainda durante alguns dias. Várias visitas se sucederam a esta e as atividades realizadas pelos licenciandos participantes do projeto foram se diversificando com a participação de diferentes professores da universidade. $\mathrm{O}$ entusiasmo e a curiosidade dos alunos que visitaram a universidade continuou muito presente nos questionamentos posteriores e reflexões sobre o que um cientista faz.

Entendemos que não temos o objetivo de definir uma imagem da Ciência ou do trabalho científico, visto que os conceitos mudam de acordo com o paradigma vigente de cada período, no entanto, é possível auxiliar os estudantes a terem outras referências sobre essas ideias. Para isso, a inserção de uma visão histórica e o contato com cientistas e com a produção científica são peças-chave para a incorporação dessa imagem maleável da ciência (PÉREZ et al., 2001; CARVALHO; COSTA; ROCHA, 2019).

\section{Considerações Finais}

A imagem de cientista destacada pelos alunos do sexto ano do ensino fundamental apresentou uma contradição entre suas repostas e os desenhos. Os textos revelaram como área de estudo a Biologia e a Física, enquanto os desenhos apresentaram um local de trabalho mais voltado para Química, com um ambiente de laboratório que comumente possui vidrarias e bancadas. As respostas dos textos podem ser resultados da influência do currículo escolar que, neste ano, enfatiza os conteúdos de Física e Biologia. Porém, os desenhos representaram imagens de cientistas mais condizentes com as veiculadas pela mídia.

O que está em concordância com a resposta sobre onde já haviam visto um cientista, e muitos alunos responderam que foi na televisão. Entretanto, é preciso estar atentos às imagens midiáticas, pois não costumam representar adequadamente a vida dos cientistas.

Entendemos a importância de atividades que possam dialogar sobre o papel da Ciência e do cientista com os estudantes, proporcionando a eles uma visão mais adequada e desmitificada sobre esses temas. Nesse sentido, os alunos conseguem perceber que todos podem se tornar cientistas e realizarem pesquisas em diferentes áreas do conhecimento, não apenas na Física e na Biologia, como também nas Ciências Humanas e Sociais. 
Assim, percebemos que, a partir da pesquisa inicial, foi possível o desenvolvimento de atividades de extensão que contribuíram com a discussão de uma temática, algumas vezes distantes das salas de aula de Ciências. Neste contexto, a extensão universitária pode protagonizar ações que favoreçam a ampliação do conhecimento dos estudantes sobre essas questões, como também possibilitar a reflexão dos licenciandos, futuros professores de Ciências Naturais, sobre a importância de incorporarem discussões acerca de temáticas que nem sempre estão presentes nos currículos escolares.

\section{Referências}

ANGOTTI, J. A. P.; AUTH, M. A. M. Ciência e Tecnologia: implicações sociais e o papel da educação. Ciência \& Educação, v. 7, n. 1, p. 15-27, 2001.

CAVALLI, M. B.; MEGLHIORATTI, F. A. A participação da mulher na ciência: um estudo da visão de estudantes por meio do teste DAST. ACTIO: Docência em Ciências, v. 3, n. 3, p. 86-2, 2018.

CARVALHO, I. L. A.; ROCHA, M. B.; COSTA, P. M. M. A visão sobre ciência nas revistas Superinteressante e Quero Saber: estudo comparativo entre Brasil e Portugal. e-Mosaicos, v. 8, n. 18, p. 72-91, 2019.

DRIVER, R.; ASOKO, H.; LEACH, J.; SCOTT, P.; MORTIMER, E. Construindo conhecimento científico na sala de aula. Química Nova na Escola, v. 9, p. 31-40, 1999.

KOMINSKY, L.; GIORDAN, M. Visões de ciências e sobre cientista entre estudantes do ensino médio. Química Nova na Escola; v.15; p. 11-18, 2002.

KRASILCHIK, M. Caminhos do ensino de ciências no Brasil. Em Aberto, v. 11, n. 55, p. 38, 1992.

LÜDKE, M.; ANDRÉ, M. E. D. A Pesquisa em educação: abordagens qualitativas. São Paulo: EPU, 1986.

OLIVEIRA, R. P. de; ARAÚJO, G. C. de. Qualidade do ensino: uma nova dimensão da luta pelo direito à educação. Revista Brasileira de Educação, v. 28, p. 5-23, 2005.

PECHULA, M. R. A ciência nos meios de comunicação de massa: divulgação do conhecimento ou reforço do imaginário social? Ciência \& Educação, v. 13, n. 2, p. 211-222, 2007. 
PÉREZ, D. G.; MONTORO, I. F.; ALÍS, J. C.; CACHAPUZ, A.; PRAIA, J. Para uma imagem não deformada do trabalho científico. Ciência \& Educação; v.7, n. 2, p. 125-153, 2001.

PRAIA, J., GIL-PÉREZ, D.; VILCHES, A. O papel da natureza da ciência na educação para a cidadania. Ciência \& Educação, v. 13, n. 2, p. 141-156, 2007.

QUEIROZ, N. L. N.; MACIEL, D. A.; BRANCO, A. U. Brincadeira e desenvolvimento infantil: um olhar sociocultural construtivista. Paidéia, v.16, n. 34, p.169-179, 2006.

RANGEL, D. O diálogo entre ciência e arte. Ciência e Cultura, v. 57, n. 4, p. 36-37, 2005.

REIS, P.; RODRIGUES, S.; SANTOS, F. Concepções sobre os cientistas em alunos do $1^{\circ}$ ciclo do ensino básico: "Poções, máquinas, monstros, invenções e outras coisas malucas". Revista Electrónica de Enseñanza de las Ciências, v. 5, n. 1, p. 51-74, 2006.

REIS, P.; GALVÃO, C. O diagnóstico de concepções sobre os cientistas através da análise e discussão de histórias de ficção científica redigidas pelos alunos. Revista Electrónica de Enseñanza de las Ciências; v. 5, n. 2, p. 213-234, 2006.

ROTTA, J. C. G.; RAZUCK, R. C. S. R.; VIVEIRO, A. A.; PORTO, F. S. Um projeto de extensão universitária como perspectiva para a realização das práticas de ensino em um curso de formação de professores. In: LEITE, C.; ZABALZA, M. (org.). Ensino superior: inovação e qualidade na docência. Porto: CIIE - Centro de Investigação e Intervenção Educativas, 2012. p. 8425-8436.

SANTANA, E. R. A abordagem da natureza da ciência subsidiada por recursos fílmicos em uma comunidade de prática. 2014. Tese (Doutorado em Educação) - Universidade de São Paulo, São Paulo, 2014.

SANTOS, E.; FARIAS, V.; ROTTA, J. C. G. A formação inicial e continuada de professores de Ciências Naturais e a extensão universitária da faculdade UnB de Planaltina. Ciências em Foco, v. 12, n. 1, p. 96-104, 2019.

SAVIANI, D. Pedagogia histórico-crítica. 11. ed. Campinas. Autores Associados, 2011.

SCHEID, N. M. J.; FERRARI, N.; DELIZOICOV, D. Concepções sobre a natureza da ciência num curso de ciências biológicas: imagens que dificultam a educação

científica. Investigações em Ensino de Ciências, v. 12, n. 2, p. 157-181, 2016.

SOUZA FILHO, M. L. Relações entre aprendizagem e desenvolvimento em Piaget e em Vygotsky: dicotomia ou compatibilidade? Revista Diálogo Educação, v. 8, n. 23, p. 265-275, 2008. 
TASSARA, E. T. O.; ARDANS, O. Intervenção psicossocial: desvendando o sujeito histórico e desvelando os fundamentos da educação ambiental crítica. In: FERRARO JÚNIOR, L. A. (org.). Encontros e caminhos: formação de educadoras(es) ambientais e coletivos educadores. Brasília: MMA, 2005.

TEIXEIRA, P. M. M. A educação científica sob a perspectiva da pedagogia histórico-crítica e do movimento C.T.S. no ensino de ciências. Ciência \& Educação, v. 9, n. 2, p. 177-190, 2003.

Recebido em: 25 de junho de 2018.

Aceito em: 19 de julho de 2020 